often repeatedly, to extremely time consuming tests that they knew could provoke uncomfortable symptoms. Financial help was provided by a research grant from the Oxford RHA(T).

\section{References}

${ }^{1}$ Reed, C E, Sosman, E, and Barbee, R D, fournal of the American Medical Association, 1965, 193, 261.

2 Hargreave, F E, et al, Lancet, 1966, 1, 445.

${ }^{3}$ Elgefors, D, Belin, L, and Hanson, L A, Scandinavian fournal of Respiratory Diseases, 1971, 52, 167.

${ }^{4}$ Fink, J N, et al, Chest, 1972, 62, 277.

${ }^{5}$ Caldwell, J R, et al, fournal of Allergy and Clinical Immunology, 1973, 52, 225.
6 Christensen, L T, Schmidt, C D, and Robbins, L, Clinical Allergy, 1975, $5,417$.

7 Faux, J A, Hendrick, D J, and Anand, B, Clinical Allergy. 1978, 8, 101. ${ }^{8}$ Hendrick, D J, et al, Thorax. In press.

${ }^{9}$ Faux, J A, et al, Clinical and Experimental Immunology, 1970, 7, 897.

10 Grant, I W B, et al, British Medical fournal, 1972, 1, 530.

${ }_{11}$ Madsen, D, et al, American Review of Respiratory Diseases, 1976, 113, 171.

12 Royal Pigeon Racing Association, personal communication, 1977.

13 Central Statistics Office, Social Trends, No 5, table 39. London, HMSO, 1974.

14 The Budgerigar Society, personal communication, 1977.

${ }^{15}$ Parkes, W R, in Occupational Lung Disorders, p 392. London, Butterworths, 1974.

${ }^{16}$ Edwards, J H, Wagner, J C, and Seal, R M E, Clinical Allergy, 1976, 6, 155.

(Accepted 6 April 1978)

\title{
Axillary hyperhidrosis treated with alcoholic solution of aluminium chloride hexahydrate
}

\author{
K T SCHOLES, K D CROW, J P ELLIS, R R HARMAN, E M SAIHAN
}

British Medical fournal, 1978, 2, 84-85

\section{Summary and conclusions}

Sixty-five patients with axillary hyperhidrosis took part in a trial of treatment with a solution of $20 \%$ aluminium chloride hexahydrate in absolute alcohol, applied topically each night for a week and then whenever the patient thought it necessary. Excellent control of sweating was achieved in 64 patients, and occlusion of the area was found to be unnecessary. No troublesome side effects were reported.

The results of this study indicate that $20 \%$ aluminium chloride hexahydrate in absolute alcohol is the treatment of first choice for patients with axillary hyperhidrosis.

\section{Introduction}

Axillary hyperhidrosis is socially embarrassing and financially taxing: suits, shirts, and dresses may be soon ruined by it. Most sufferers are extremely conscious of the wet patches evident in their axillae on important social occasions. The main feature of the disorder is a massive outpouring of secretions from the eccrine sweat glands under thermal and emotional stress. It is virtually unknown before adolescence, and many patients seem to undergo spontaneous remission after middle age.

Many forms of treatment have been advocated, which were well reviewed by Cunliffe and Tan. ${ }^{1}$ There are four main types: systemic, surgical, radiotherapeutic, and topical. Systemic treatment consists mainly of anticholinergic drugs such as propantheline. These often have to be given in high dosage, causing severe side effects with little control of axillary sweating.

\footnotetext{
Department of Dermatology, Princess Margaret Hospital, Swindon SN1 4JU

K T SCHOLES, MB, CHB, clinical assistant

K D CROW, MB, FRCP, consultant dermatologist

J P ELLIS, MB, MRCP, consultant dermatologist

Department of Dermatology, Bristol Royal Infirmary, Bristol BS2 8HW

R R HARMAN, MB, FRCP, consultant dermatologist

E M SAIHAN, MB, MRCP, registrar
}

Various operative procedures described include cervical sympathectomy, ${ }^{2}$ total excision, ${ }^{3}$ or curettage ${ }^{4}$ of the eccrine glands, and cryotherapy. ${ }^{5}$ Ellis ${ }^{6}$ advocated total excision of the eccrine glands as the treatment of choice. The initial success rate of this procedure appears to be low, however, recurrence is high, and scarring may be severe. Radiotherapy has also been used, ${ }^{7}$ but the high dose needed to eliminate sweating may cause radiodermatitis. Many topical preparations have been in common usage from the early part of the century: Shelley and Hurley : listed almost 90, most of which were aluminium salts. Their mode of activity is not known, but they affect the eccrine gland and duct below the level of the stratum corneum rather than plugging the sweat pore. ${ }^{8}{ }^{9}$ These preparations have been used extensively commercially but are usually buffered towards a neutral $\mathrm{pH}$ to minimise irritation of the skin and damage to clothing, which makes them more acceptable. They appear to control sweating in normal people but do not help those with hyperhidrosis.

Shelley and Hurley ${ }^{7}$ maintained that a high acidity $(\mathrm{pH}<1)$ was essential in treating patients with hyperhidrosis, and claimed success in five cases in which a $25 \%$ solution of aluminium chloride hexahydrate in absolute alcohol was used. Their work seems to have been largely overlooked, but their results were encouraging and we felt they justified further study, particularly in view of the cases reported by Sneddon. ${ }^{10}$

\section{Patients and methods}

Over 15 months we treated 65 patients with axillary hyperhidrosis in our dermatology clinics (42 in Swindon and 23 in Bristol). The group comprised 57 women and eight men aged $14-51$ years. They had suffered from axillary hyperhidrosis for from two to 25 years. Many had had previous treatments. In particular, three had undergone excision of the eccrine glands, and one had been treated with sympathetic block and radiotherapy. The diagnosis of axillary hyperhidrosis was made from the patient's history and close observation of the axilla at consultation. In every case the sweat soaked through clothing.

Our methods were based on those outlined by Shelley and Hurley,? using $20 \%$ aluminium chloride hexahydrate dissolved in absolute alcohol. This is an almost saturated solution and takes three weeks to dissolve at room temperature. The solution was applied nightly with a small brush. It was important that the axilla was dry before application and not shaved for 24 hours before and after treatment. The solution was applied only to the area of excessive sweating. At the beginning of the study the patients were instructed to occlude the 
axilla with thin polyethylene film held in place with cotton-wool balls and crêpe bandage. After using this irksome regimen for six months one patient reported that control of sweating was achieved just as readily without occlusion. Accordingly we instructed our patients to apply the solution without an occlusive dressing, and subsequent experience showed that this element of Shelley and Hurley's method is unnecessary. The morning after application the axilla was washed thoroughly with soap and water. Nightly applications were continued for one week, after which the patient applied the solution only when necessary.

\section{Results}

All the patients were followed up closely in the two departments, and after 12 months a questionnaire was sent to the Swindon group asking for their comments. Sixty-four patients were highly delighted with the treatment and had achieved complete control of axillary sweating by periodic use of the solution. We felt that the high rate of return of the questionnaire in Swindon (41 out of 42 returned in two weeks) also reflected their satisfaction. After the initial period of nightly treatment the interval between applications varied from two days to one year. Most patients, however, had to apply the solution once every seven to 21 days to maintain control. The only side effect mentioned was irritation of the axillary skin, which we presume is caused by the high acidity of the solution. Twenty-nine experienced some irritation, but 28 of these said that it was readily relieved by applying $1^{\circ}$ " hydrocortisone cream on the morning after treatment. Some of these patients also found that they could reduce the irritation by applying the solution more accurately to the area of excessive sweating. One patient, who had the least severe hyperhidrosis, had to stop treatment because of unbearable irritation.

\section{Discussion}

This trial was highly successful, and we think that $20^{\circ}$ \% aluminium chloride hexahydrate in absolute alcohol should be considered to be the treatment of first choice in axillary hyperhidrosis. In particular, the troublesome occlusive dressing recommended by Shelley and Hurley ${ }^{7}$ was found to be unnecessary, which makes the treatment much more acceptable to the patient. Preparation of the solution has been described as laborious, ${ }^{11}$ but this has not been our experience. Our hospital pharmacists report that if the mixture of aluminium chloride hexahydrate crystals and absolute alcohol is left at room temperature and shaken occasionally a $20 \%$ solution may be produced in three weeks. A local chemist has also made the solution without difficulty. Using absolute alcohol means paying excise duty, which increases the cost of the preparation. Thus we now use a lower-proof spirit $(95-99.5 \%)$, and initial results indicate no diminution of effect.

Irritation of the axilla was the only side effect reported and was almost always readily relieved by $1 \%$ hydrocortisone cream. Most of the patients were so delighted with the control of their sweating that they would tolerate minor irritation for a few hours every fortnight. Although the solution was highly acidic, we received no complaints of damage to clothing. Nevertheless, one patient reported total destruction of his passport when the bottle broke in his suitcase.

We are now extending our work to include excessive sweating at other sites and have had similar encouraging results with sweat reduction on the palms and soles and, in one patient, the forehead. We are reporting these results as early as possible because we think that there is no longer any indication for surgical treatment of axillary hyperhidrosis and that such operative procedures should be avoided.

\section{References}

1 Cunliffe, W J, and Tan, S G, Practitioner, 1976, 216, 419.

2 Greenhalgh, R M, Rosengarten, D S, and Martin, P, British Medical fournal, 1971, 1, 332

${ }^{3}$ Hurley, H J, and Shelley, W B, Fournal of the American Medical Association, 1963, 196, 109

4 Jemec, B, Scandinavian fournal of Plastic and Reconstructive Surgery, 1975, 9,44

${ }^{5}$ Ashby, E C, and Williams, J Ll, British Medical fournal, 1976, 2, 1173.

${ }^{6}$ Ellis, H, British Medical fournal, 1977, 2, 301.

Shelley, W B, and Hurley, H J, Acta Dermato-venereologica, 1975, 55, 241.

${ }^{8}$ Papa, C M, and Kligman, A M, fournal of Investigative Dermatology, 1967, 49, 139.

${ }^{9}$ Gordon, B I, and Maiback, H I, Fournal of Investigative Dermatology, 1968, 50, 411 .

10 Sneddon, I B, British Medical fournal, 1976, 2, 1447.

${ }^{11}$ Ryan, T J, Medicine, 1977, 32, 1871.

\title{
Proctocolectomy without ileostomy for ulcerative colitis
}

\author{
A G PARKS, R J NICHOLLS
}

British Medical fournal, 1978, 2, 85-88

\section{Summary and conclusions}

An operation has been developed that permits total removal of all disease-prone mucosa in ulcerative colitis but avoids the need for a permanent ileostomy. The colon and upper half of the rectum are excised and the remaining inflamed mucosa is stripped from the rectal stump down to the dentate line of the anal canal. A pouch is fashioned from a triplicated loop of terminal ileum.

\footnotetext{
St Mark's Hospital, London EC1V 2PS and London Hospital, London E1 2AD

Sir ALAN G PARKS, FRCS, FRCP, consultant surgeon

R J NICHOLLS, MCHIR, FRCS, senior surgical registrar
}

This is drawn down through the denuded rectum and an anastomosis created, via the per-anal approach, between the ileum just distal to the pouch and the mid-anal canal. A temporary ileostomy is made.

Out of eight patients so treated, five were available for assessment, and four of them were highly satisfied with the result in improved health and function. The remaining three were awaiting closure of their ileostomies.

\section{Introduction}

Ulcerative colitis is of unknown aetiology, and its treatment, both medical and surgical, is empirical. Operative treatment will remain an essential part of management until the cause of the disease is found and a specific cure discovered. Proctocolectomy is the commonest procedure used and eliminates colonic mucosa in its entirety and thus the source of inflammation and potential malignancy. The price paid, however, is a permanent ileostomy. 